\title{
Protagonistas na Sociedade Civil: Redes e Centralidades de Organizações Civis em São Paulo*
}

\author{
Adrian Gurza Lavalle \\ Graziela Castello \\ Renata Mirandola Bichir
}

\section{INTRODUÇÃO}

\begin{abstract}
A extraordinária atenção suscitada pela sociedade civil no mundo acadêmico e nos circuitos nacionais e internacionais de formuladores de políticas públicas contribuiu, paradoxalmente, para eclipsar as organizações civis reais, sua diversidade, lógicas de atuação e dinâmicas de interação com outros atores. Nas últimas duas décadas, foram empenhados inúmeros esforços ao desbravamento do terreno analítico, de modo a conferir precisão conceitual à categoria Sociedade Civil, investindo-a, a um só tempo, de estatuto político normativo capaz de centrá-la como peça-chave de novo projeto para democratizar a democracia. Por motivos outros, múltiplos atores multilaterais, governamentais e societários também granjearam, nesses anos, novo estatuto para a chamada sociedade civil, agora portadora inconteste de virtualidades positivas para o gerenciamento local e focalizado de políticas públicas e para impulsionar a boa governança. Independentemente do mérito de tais esforços, sem dúvida foram bem-sucedidos, se julgados pelos seus efeitos de proliferação: a literatura acadêmica centrada na sociedade civil é hoje quase incomensurável; as transferências financei-
\end{abstract}

\footnotetext{
*Os resultados apresentados neste artigo fazem parte do projeto Rights, Representation and the Poor: Comparing Large Developing Country Democracies - Brazil, Indian and Mexico (disponível em http://www.ids.ac.uk/gdr/cfs/research/Collective\%20 Actors.html).
}

DADOS - Revista de Ciências Sociais, Rio de Janeiro, Vol. 50, n-3, 2007, pp. 465 a 498. 
ras de organismos multilaterais, governos e agências financiadoras do hemisfério norte para organizações não-governamentais - ONGs do hemisfério sul aumentaram em proporções galopantes ${ }^{1}$; isso sem esquecer, é claro, as inovações institucionais participativas que, no Brasil e pelo mundo afora, têm estimulado a intervenção de organizações civis no desenho e implementação de políticas públicas.

Porém, malgrado e em boa medida graças a semelhante sucesso, sabe-se surpreendentemente pouco acerca do modus operandi das organizações civis reais, mesmo daquelas que têm sido constantemente salientadas na literatura devido à emergência de protagonismos inéditos. Embora seja compreensível a presença rala na literatura de atores "miúdos", ora por seu perfil acanhado, ora por carecerem de implicações atraentes quando olhados através das lentes das teorias, espanta a ausência de conhecimento sistemático e cumulativo sobre o funcionamento real de atores "graúdos" - inclusive no caso de organizações civis como as ONGs, consensualmente assinaladas na literatura como grande protagonista dos anos 1990. Com efeito, caracterizações altamente estilizadas de uma esfera de ação societária circunscrita por princípios unificadores comuns e por nítida diferenciação em relação ao Estado e ao mercado alimentaram consensos largamente difundidos sobre as potencialidades da sociedade civil - por sinal, consensos pouco sensíveis às diferenças internas, conflitos, afinidades, hierarquias e modalidades de articulação próprias ao universo das organizações civis reais.

Contra esse pano de fundo, este artigo visa trazer à tona e avançar na apuração de uma questão que, a despeito da sua relevância, tem recebido tratamento precário na literatura: como funcionam as organizações civis ${ }^{2}$ Isto é, quais as diferentes lógicas de atuação e dinâmicas internas de interação que organizam o universo desses atores societários, particularmente daqueles que têm se notabilizado nos últimos anos por seu protagonismo ou capacidade de atuação? Trata-se de avançar na elaboração de respostas alicerçadas na produção de conhecimento empírico, pelo que a própria definição dos atores com maior capacidade de atuação constitui um resultado empírico, evitando-se assim deduzir protagonismos a partir da literatura. Nesse sentido, a idéia de sociedade civil permanece aqui reservada apenas para remeter àquela perspectiva geral e estilizada existente na literatura, com ecos claros nas comunidades internacionais de formuladores de políticas, mas nunca aos atores empíricos estudados. Para eles utiliza-se o termo or- 
ganizações civis, mais neutro e, de certo, menos estilizado e normativamente sobrecarregado ${ }^{3}$.

Desse modo, a partir de estratégia de análise de redes aplicada aos resultados de survey realizado na cidade de São Paulo em 2002, o funcionamento das organizações civis com maiores capacidades de atuação ou mais centrais será aqui reconstruído mediante diversos recortes analíticos a serem expostos no decorrer deste artigo. As vantagens cognitivas de se utilizar análise de redes para abordar conjuntos de atores normalmente encobertos pela categoria sociedade civil são conhecidas e têm recebido atenção alhures ${ }^{4}$.

Neste caso, os recortes analíticos adotados revelaram padrões de relacionamento com conseqüências pertinentes para entender o funcionamento das organizações civis. Primeiro, trata-se de um universo de atores altamente hierarquizado, em que organizações populares, ONGs e articuladoras ocupam posições centrais privilegiadas por maiores capacidades de ação e escolha. Em Gurza Lavalle, Castello e Bichir (2006) foi mostrado que associações de bairro e comunitárias são claramente periféricas, enquanto os fóruns e as entidades assistenciais se situam em posição intermediária. Segundo, os tipos de organizações civis melhor articuladas entre si correspondem, precisamente, àquelas que também ocupam posições privilegiadas na rede como um todo. Terceiro, verificou-se a existência de vínculos preferenciais entre certos tipos de organização que seguem sempre a mesma direção: das entidades periféricas para aquelas mais centrais e, como era de esperar, das organizações com posições privilegiadas para outras organizações igualmente privilegiadas. Porém, entidades podem ocupar posições privilegiadas ou ter capacidades de atuação limitadas por diversos motivos e desempenhando papéis muito diferentes. É neste terreno que os resultados são mais valiosos, pois permitem caracterização relacional do funcionamento das organizações civis estudadas. Aqui serão salientados apenas os principais achados contra-intuitivos e as feições mais relevantes do funcionamento dos tipos de organização civil mais centrais, de modo a atentar para lacunas no estado do conhecimento sobre os atores estudados - lacunas iluminadas ou "descobertas" a partir de uma perspectiva relacional.

Os resultados apresentados são produto de um survey levado a cabo no município de São Paulo, ao longo de seis meses de trabalho de campo, no ano de 2002. Os critérios de escolha favoreceram organizações civis 
ativas, particularmente aquelas engajadas nos segmentos mal-aquinhoados da população ${ }^{5}$. Os diversos tipos de atores e o conhecimento estabelecido na literatura sobre eles serão abordados nas próximas seções, e, depois, serão explicitadas a estratégia de análise de redes aqui ensejada e a metodologia correspondente. Uma síntese dos resultados gerais, seguida do exame e interpretação detalhados das diferentes modalidades de protagonismo inerentes aos atores centrais analisados ocupará as penúltimas seções. O artigo encerra com breve comentário final.

\section{ATORES CENTRAIS}

Os rótulos normalmente utilizados para distinguir atores societários são objeto de disputa simbólica para atribuir sentido a seu agir, e, portanto, a assunção de uma determinada denominação por parte das entidades entrevistadas obedece a uma série de cálculos de auto-apresentação pública, destinados a posicioná-las em campos específicos do mundo das organizações civis perante interlocutores determinados. No intuito de contornar essa dificuldade, as organizações civis não foram classificadas com base em suas autodefinições, mas conforme critérios objetivos de duas ordens: a relação com seus beneficiários e o perfil das atividades normalmente realizadas. No primeiro caso, o conjunto dos beneficiários encarna uma unidade real ou abstrata (por exemplo, os moradores do bairro ou os cidadãos, respectivamente), cujos componentes são indivíduos, organizações e atores coletivos, ou segmentos da população concebidos como membros ou sócios, como público-alvo, ou como a comunidade. No segundo, a cada tipo de associação corresponde uma estratégia de atuação distintiva e combinações excludentes de atividades orientadas para a reivindicação e mobilização, para o fornecimento de serviços, para a organização popular, ou para a intermediação entre o governo e os beneficiários.

Mediante a aplicação desses critérios, tornou-se possível delinear uma tipologia de atores notabilizados por seu protagonismo dentro do universo das organizações civis. Por exemplo, no primeiro caso, as ONGs costumam trabalhar para beneficiários definidos em termos de uma unidade abstrata, composta por determinados recortes ou segmentos da população concebidos não como membros ou sócios, mas como público-alvo. No segundo, sua estratégia de atuação distintiva normalmente é a tematização pública de problemas trabalhados dentro de uma semântica política de direitos cidadãos e/ou hu- 
manos; nesse sentido, é raro definirem o perfil das suas atividades a partir da mobilização dos eventuais beneficiários ou da organização popular - antes, centram-nas em combinações diferentes de prestação de serviços e de intermediação simbólica ou material entre o poder público e a sociedade.

Dado o caráter empírico da tipologia, outros tipos de organizações civis foram encontrados, mas em virtude da sua posição periférica na rede não receberão tratamento neste artigo. Contudo, a categoria Demais Atores não é residual: de um lado, adiciona os resultados, separadamente calculados, de quatro tipos de organizações civis definidos empiricamente conforme os mesmos critérios e cujas posições na rede revelaram-se intermediárias ou francamente periféricas; de outro, funcionará como categoria de referência na ordenação dos dados a serem examinados nos primeiros dois recortes analíticos. Fóruns, entidades assistenciais, associações de bairro e associações comunitárias são assim grupados sob a mesma rubrica, e não devido aos seus resultados individuais, mas porque a análise agregada mostrou se tratar de tipos de atores claramente diferenciados em relação às organizações civis centrais ${ }^{6}$.

A relação entre a tipologia e as caracterizações disponíveis na literatura será abordada na próxima seção. O Quadro 1 sistematiza a tipologia, informa a freqüência relativa de cada tipo e oferece exemplos das organizações civis classificadas. A composição da amostra obedece a critérios expostos na seção Centralidade, Análise de Redes e Survey. Cumpre mencionar que testes empíricos não revelaram outras formas de agrupação contrárias ou mais consistentes que os critérios analíticos aqui utilizados.

\section{A LITERATURA E AS CARACTERIZAÇÕES}

A distância entre a tipologia e as caracterizações existentes na literatura é menor no caso dos atores que maior atenção têm recebido, tal como ocorre com as ONGs. Embora a denominação organização não-governamental, oriunda dos organismos de cooperação internacional, tenha sido utilizada de modo corrente como termo genérico na literatura internacional, no Brasil corresponde stricto sensu às organizações civis conhecidas na literatura anglo-saxônica como entidades de advocacy dedicadas a vocalizar ou reivindicar publicamente as demandas e necessidades de terceiros. Se na sua origem foram concebidas como enti- 


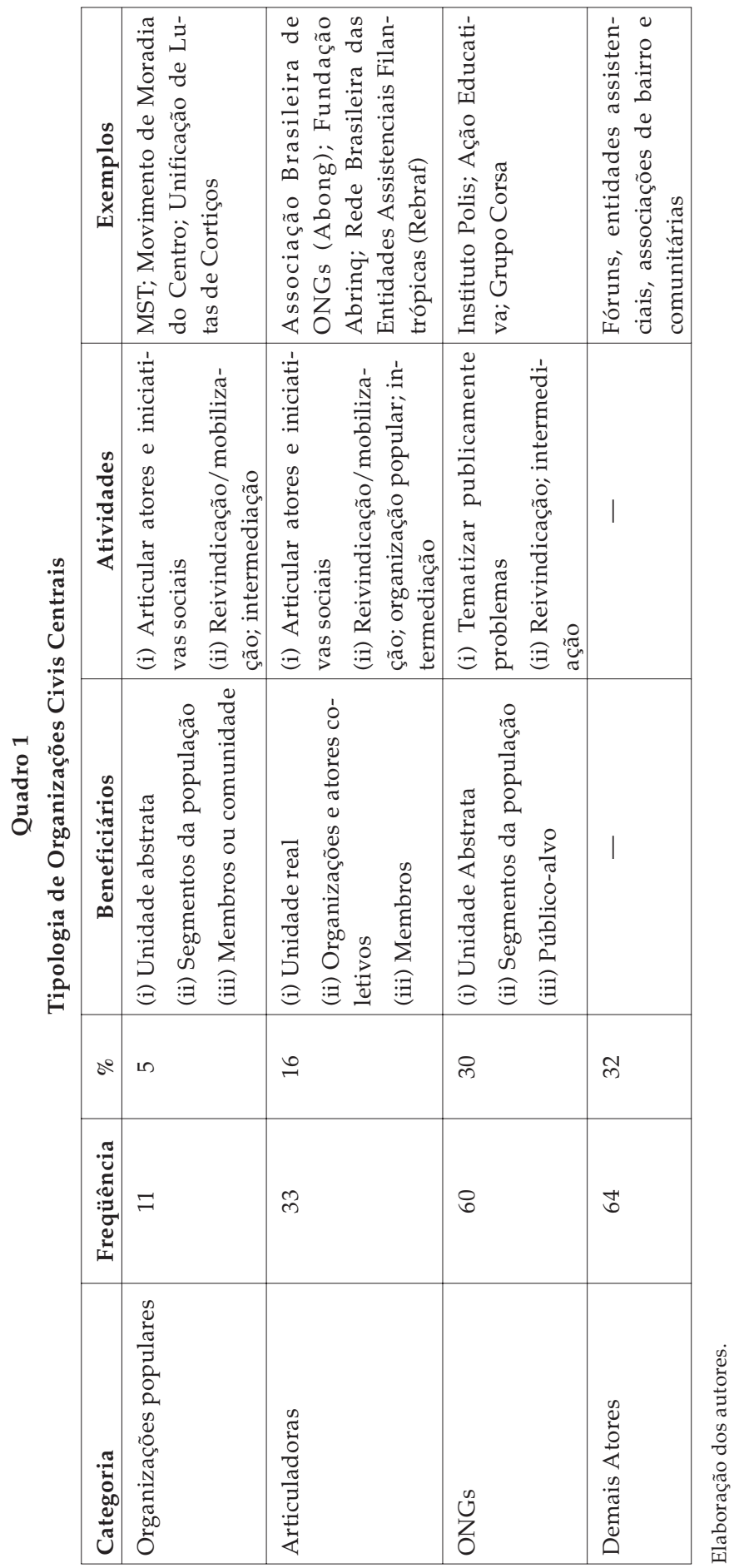


dades de assessoria aos movimentos sociais, há consenso amplo na literatura nacional quanto ao fato de as ONGs terem se tornado os atores de maior destaque no cenário da ação coletiva nos anos $1990^{7}$. Também há consenso no que diz respeito a certas feições recorrentes na sua caracterização, a saber, discurso elaborado dentro de uma semântica de direitos e de ampliação substantiva da democracia, orientação temática, ação voltada à publicização de problemas e coordenação com outros atores mediante trabalho em rede (ver, por exemplo, Landim, 1996) ${ }^{8}$. A definição de para quem trabalham as ONGs é menos pacífica na literatura, pois mesmo se aceita essa função de mediação capaz de transitar "entre os locais românticos das comunidades tradicionais e os esclarecidos territórios da cidadania" (Fernandes, 1994:76), ou sua conhecida origem como entidades de apoio aos movimentos populares" ${ }^{9}$ parece inescapável reconhecer que "tal função de mediação é unilateral" (idem:78). A compreensão dos beneficiários do trabalho dessas organizações em termos de público-alvo, a despeito de parcialmente controversa, aponta precisamente para essa unilateralidade ${ }^{10}$.

Uma segunda categoria da tipologia também tem sido amplamente estudada, embora sob denominação diferente. Organizações populares correspondem em parte àqueles atores que, a partir dos anos $1970 \mathrm{e}$, sobretudo, nos anos 1980, passaram a ser denominados e pensados no registro das teorias dos movimentos sociais - especialmente para apreender a lógica de atuação de atores específicos voltados para a mobilização coletiva a propósito de demandas populares. À margem das orientações teóricas mais influentes na literatura sobre movimentos sociais ${ }^{11}$, o conceito apresenta problemas de ambigüidade na sua definição: tem sido utilizado igualmente na definição de atores empíricos específicos, normalmente portadores de capacidade de contestação perante o Estado - Movimento dos Sem-Terra - MST, Movimento dos Atingidos por Barragens - MAB -, e na unificação analítica de conjuntos esparsos de iniciativas individuais e coletivas sintonizadas ao longo do tempo por afinidades de sentido - movimento feminista, movimento negro, movimento de saúde. O universo de atores aqui definidos como organizações populares corresponde à primeira acepção. Salvo raras exceções (ver Feltran, 2005; Mendonça, 2002; Marteleto, Ribeiro e Guimarães, 2002), os movimentos sociais registraram misterioso sumiço na literatura a partir do início dos anos 1990, em boa medida graças ao encerramento do ciclo da transição e à conseqüente estabilização e institucionalização da política e do protesto social, mas também devido a mudanças nas categorias analíticas utilizadas - ago- 
ra convertidas ao registro heurístico da sociedade civile/ou das ONGs (Gurza Lavalle, Castello e Bichir, 2004; Sobottka, 2002). A onda de balanços desiludidos do final dos anos 1980, apontando para a desmobilização e cooptação dos atores, bem como para a ingenuidade e otimismo dos autores, parece ter prenunciado um certo abandono do conceito ${ }^{12}$. De fato, não é raro se deparar ainda hoje com diagnósticos que reafirmam o esmaecimento dos movimentos e a despolitização generalizada da ação coletiva, imputando semelhante panorama aos efeitos corrosivos do ajuste estrutural (ver Casanovas Sainz e García Chacón, 2000:63-67; Rucht, 2002) ${ }^{13}$. Seja como for, aos movimentos sociais foi e é conferida uma capacidade de ação coletiva centrada na construção de novas identidades (Evers, 1984; Touraine, 1989; Sader, 1988; Melucci, 1989), normalmente não absorvíveis dentro do universo das instituições tradicionais de representação de interesses; também lhes é imputado um protagonismo altamente espontâneo, devido à exigência de uma mobilização não-burocratizada ou corporativizada.

Embora as entidades denominadas articuladoras na tipologia ocupem novo espaço no cenário da ação coletiva institucionalizada, não têm recebido atenção na literatura ou, com maior precisão, é regra serem rotuladas como ONGs - e em menor medida como organizações populares - e tratadas, assim, de modo indiferenciado sob essa rubrica ${ }^{14}$. O empenho das ONGs na criação de redes e de espaços de coordenação é amplamente reconhecido, todavia, articuladoras diferem significativamente das ONGs em aspectos relevantes: são fundadas por outras entidades com o intuito de coordenar e articular suas ações, de construir agendas comuns e de escalar sua capacidade de agregação de interesses com fins de representação perante o poder público e outros atores sociais. Por outras palavras, as articuladoras podem ser classificadas como organizações civis de terceira ordem, distintas tanto daquelas instituídas sob o signo da identidade entre beneficiários das associações e seus fundadores, administradores ou trabalhadores - organizações civis de primeira ordem como as associações de bairro ou as de caráter comunitário -, quanto daquelas outras estabelecidas para beneficiar terceiros definidos como pessoas ou segmentos da população - nesse sentido, de segunda ordem, como as entidades assistenciais e as ONGs.

\section{CENTRALIDADE, ANÁLISE DE REDES E SURVEY}

A análise de redes sociais assume como premissa a importância dos laços sociais como elementos que estruturam a vida social, imputando a 
eles diversas conseqüências em termos de possibilidades e restrições para a ação de indivíduos e atores coletivos. A unidade de análise utilizada são as relações estabelecidas entre pessoas e entre entidades, e não os indivíduos ou organizações em si e sequer seus atributos. Como estratégia analítica, situa-se em plano cognitivo intermediário, trazendo consigo mudanças de perspectiva tanto na compreensão do plano macro quanto do micro (Emirbayer, 1997). É importante destacar que, a rigor, a análise de redes sociais não constitui uma teoria, tampouco um conjunto de técnicas estatísticas complexas, mas uma estratégia analítica passível de utilização à luz de diferentes perspectivas conceituais e teóricas ${ }^{15}$.

Assume-se aqui que o protagonismo das organizações civis é expressão de sua capacidade de atuação - a qual, na análise de redes, depende do posicionamento do ator em uma teia de relações ${ }^{16}$. Um ator central no interior de uma dada rede é aquele que, a partir de um número considerável de relações, consegue exercer grande influência sobre os demais atores e gerar neles certa dependência, controlando diversas possibilidades de fluxos e desfrutando uma capacidade maior de fazer escolhas dentro de seu universo de relações (Hanneman, 2001). Enquanto as escolhas a parecem associadas à capacidade de ação ou agência, os fluxos remetem a bens materiais e imateriais cuja natureza varia enormemente dependendo dos atores contemplados pela análise. Ademais, atores centrais ocupam posições estratégicas no interior da rede, sendo importante considerar não apenas os vínculos diretos com outros atores, mas também aqueles de caráter indireto (Wasserman e Faust, 1994). A centralidade no interior de uma rede surge como conseqüência dos padrões de relações estabelecidos entre os atores e, portanto, não é um atributo ou "posse" dos atores em si (Scott, 1992). Em suma, a noção de centralidade está associada à noção de capacidade de ação, quer dizer, de escolha entre diversas alternativas possíveis e de autonomia em relação aos vínculos estabelecidos com atores específicos.

Embora existam diversas ferramentas analíticas disponíveis no âmbito da metodologia de análise de redes, a maior parte dos resultados aqui expostos exprimem medidas de centralidade ${ }^{17}$, utilizadas para destacar a posição relativa de cada um dos atores considerados dentro do universo das organizações civis. Grosso modo, na análise foram empregadas sete medidas ${ }^{18}$. Procurou-se identificar tanto as organizações da sociedade civil que funcionam como referências ou detêm prestígio no conjunto das organizações, sendo muito citadas (número de vínculos 
recebidos - indegree), quanto aquelas caracterizadas por citar muitos parceiros (número de vínculos enviados - outdegree) ${ }^{19}$. Também foi analisada a relação entre tipos de organizações civis e suas capacidades de intermediação (betweenness) e articulação de diferentes sub-redes; capacidades que permitem impedir ou facilitar o contato entre diversas entidades, bem como controlar os fluxos entre elas. Outra forma de caracterização da centralidade consistiu na observação das organizações civis relativamente mais próximas das outras - proximidade (closeness) passível de ser traduzida em capacidade de ação e de coordenação. Examinou-se igualmente a assimetria das relações existentes entre as organizações civis, aferindo a dependência produzida por certas entidades sobre outras, ou o poder de determinada entidade (power). Procurou-se diferenciar, ainda, as organizações que lançam mais vínculos daquelas que são preponderantemente receptoras de vínculos, apresentando diferentes tipos de influência (influence). Procurou-se destacar, também, as organizações com maior acesso à informação (information) no interior da rede, isto é, ao controle de certos fluxos preferenciais entre o conjunto de relações disponíveis.

De uso mais modesto nesta análise, algumas medidas de coesão foram empregadas com o intuito de determinar o modo de estruturação dos atores e suas relações no interior de uma rede, abordando aspectos como o tamanho da rede, sua densidade, as distâncias existentes entre cada um dos atores (geodesic distance) e o número de atores que podem ser alcançados no interior da rede (reachability). Além disso, também foram utilizadas representações gráficas das redes - sociogramas - tanto para introduzir subsídios de caráter mais qualitativo à análise quanto para tornar mais fácil a compreensão dos resultados mediante representações visuais peculiarmente elucidativas.

Uma vez que a expressão numérica das medidas de centralidade parece complexa e carece de referentes empíricos óbvios, optou-se por apresentar resultados simplificados. Para tanto, os resultados das medidas de redes para os atores centrais - apresentados em tabelas-resumo - foram convertidos ou em porcentagens, sempre em relação à média dos Demais Atores na amostra - tomada como valor de referência -, ou em ranking simples. As denominações técnicas das medidas também foram simplificadas.

Todas as informações relacionais necessárias para análise de redes aqui apresentada foram obtidas por meio de entrevistas realizadas 
com 202 organizações civis, na mencionada pesquisa realizada no município de São Paulo em $2002^{20}$. Foi utilizada a técnica bola de neve (snowball) - bastante comum em análises de redes sociais (Scott, 1992). Ao todo, as entrevistas com essas entidades geraram um total de 741 atores diferentes citados e 1.293 relações diretas levantadas. Na medida em que cada entidade entrevistada pôde citar até cinco relações em ordem de importância ou as mais próximas para diferentes tipos de entidades, as redes aqui examinadas representam a malha mais densa de relações existentes entre as organizações civis paulistanas pesquisadas - não a totalidade de vínculos existentes. Cada relação direta incrementa exponencialmente o número de relações indiretas e, por isso, há um total de 549.081 relações possíveis. O universo das entidades pesquisadas não foi definido a priori, mas empiricamente como base nas cadeias de referências fornecidas, a partir de 16 pontos de entrada, pelos atores entrevistados ${ }^{21}$.

\section{PADRÕES DE RELACIONAMENTO DAS ORGANIZAÇÕES CIVIS CENTRAIS}

Esta seção apresenta de modo sintético os principais resultados referentes aos padrões de relações das organizações civis com maiores capacidades de atuação. A interpretação dos padrões encontrados será efetuada na seção seguinte. As relações foram examinadas a partir de três ângulos ou recortes analíticos. No primeiro caso, para distinguir os papéis desenvolvidos pelos diferentes tipos de organizações civis, centra-se o foco na relação entre cada tipo e o universo das organizações como um todo; no segundo, examinam-se cuidadosamente apenas as conexões internas próprias a cada tipo de organização civil (por exemplo, ONGs com ONGs), como se se tratasse de esquadrinhar subcampos caracterizados por lógicas relacionais distintas; no terceiro, opera-se novo recorte sobre as inter-relações mais freqüentes entre tipos de entidades distintos, mostrando claramente afinidades e distâncias que organizam as relações dos atores centrais no universo das organizações civis na cidade de São Paulo. Cada recorte apresenta contribuições específicas para o entendimento das dinâmicas de funcionamento das organizações civis.

O principal resultado a ser destacado, do ponto de vista da inserção das organizações civis na rede como um todo ${ }^{22}$, refere-se à marcada estratificação das diversas organizações civis. Há três tipos de entidades que ocupam posições altamente centrais, enquanto os demais atores se situam em posições periféricas ou intermediárias, acusando depen- 
dência em relação às primeiras. Os dados apresentados na Tabela 1 evidenciam o contraste; os números exprimem, para cada medida, a posição relativa dos tipos de organizações civis examinados em relação aos Demais Atores da amostra; isto é, o quanto (\%) os tipos mais centrais se aproximam ou se afastam da média dos resultados médios dos tipos de entidade compreendidos nos Demais Atores ${ }^{23}$. Assim, por exemplo, as articuladoras realizam 139\% mais intermediação do que os Demais Atores.

Os resultados apontam de modo consistente para o papel protagônico desses três tipos de entidades dentro do universo das organizações civis paulistanas: organizações populares, articuladoras e ONGs - nessa ordem. Essas entidades ocupam as posições mais centrais tanto pela quantidade de vínculos enviados e recebidos quanto pela sua capacidade de intermediação e de difusão de informação, e, no caso das organizações populares e das articuladoras, também pelo balanço favorável entre as relações enviadas e recebidas (influência). Nesse balanço e na clara dependência gerada por ambos os tipos de organizações nas outras entidades (poder), percebe-se marcado contraste com o padrão de centralidade das ONGs - as quais não geram dependência nem recebem mais vínculos do que enviam. No caso das medidas de coesão, bem como nos dados de proximidade, a variação geral dos resultados é muito menor, mas ainda assim as organizações em questão apresentam posições relativamente favoráveis.

O segundo recorte analítico foca as relações internas entre as organizações civis de cada tipo (Tabela 2). Os resultados indicam que os atores caracterizados por apresentarem organicidade e complexidade desproporcionalmente maiores nas suas relações internas correspondem, exatamente, àqueles que ocupam posições mais centrais na rede como um todo; e isso aponta para uma estreita relação entre os modos de organização interna dos diferentes tipos de entidades e os papéis por eles desempenhados no universo das organizações civis. A rede interna das organizações populares é de longe a mais densa em termos do número de vínculos, aquela em que há mais intermediação interna - algumas organizações populares atuam como pontos de passagem necessários para todas as outras - e em que os atores estão relativamente mais próximos entre si. Com redes consideravelmente maiores, obstando a proximidade interna, articuladoras e ONGs apresentam feições semelhantes, embora atenuadas. Cabe destacar que a ausência de dependência constitui traço complementar da maior organicidade e 
Protagonistas na Sociedade Civil: Redes e Centralidades de Organizações...

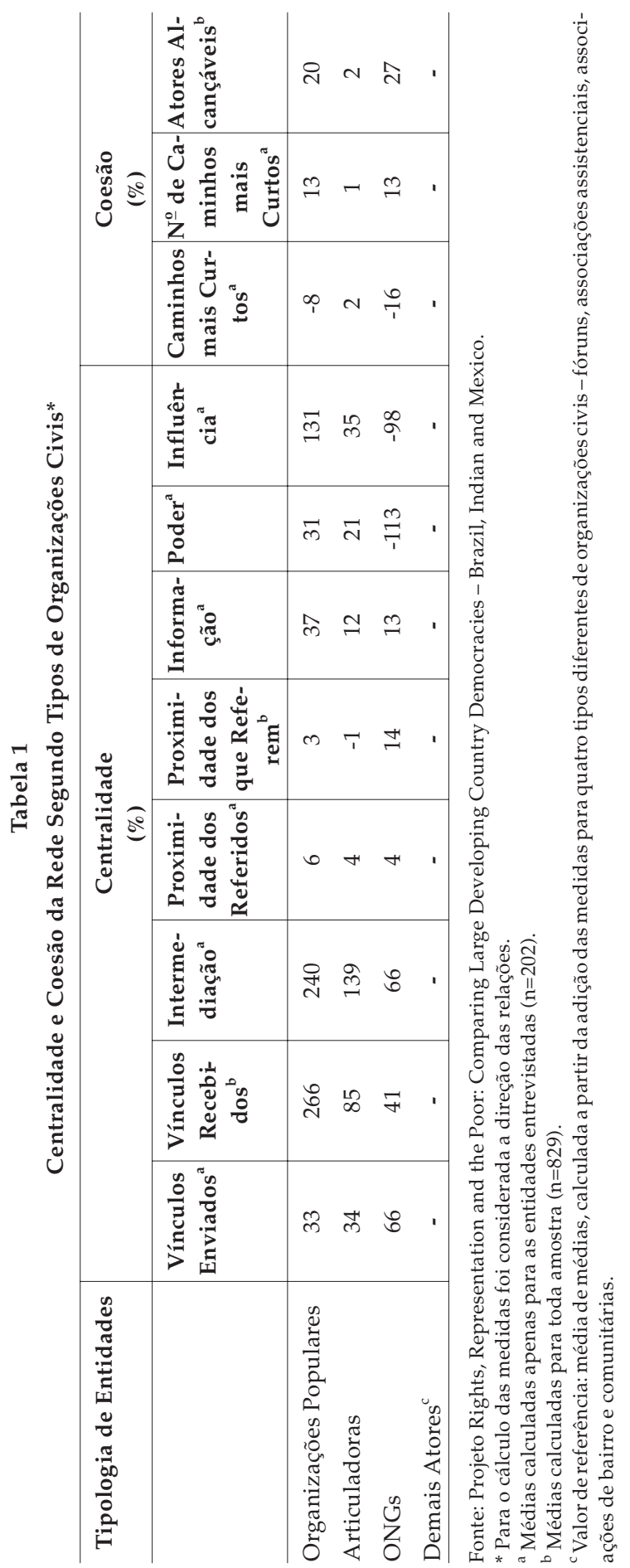


Adrian Gurza Lavalle, Graziela Castello e Renata Mirandola Bichir

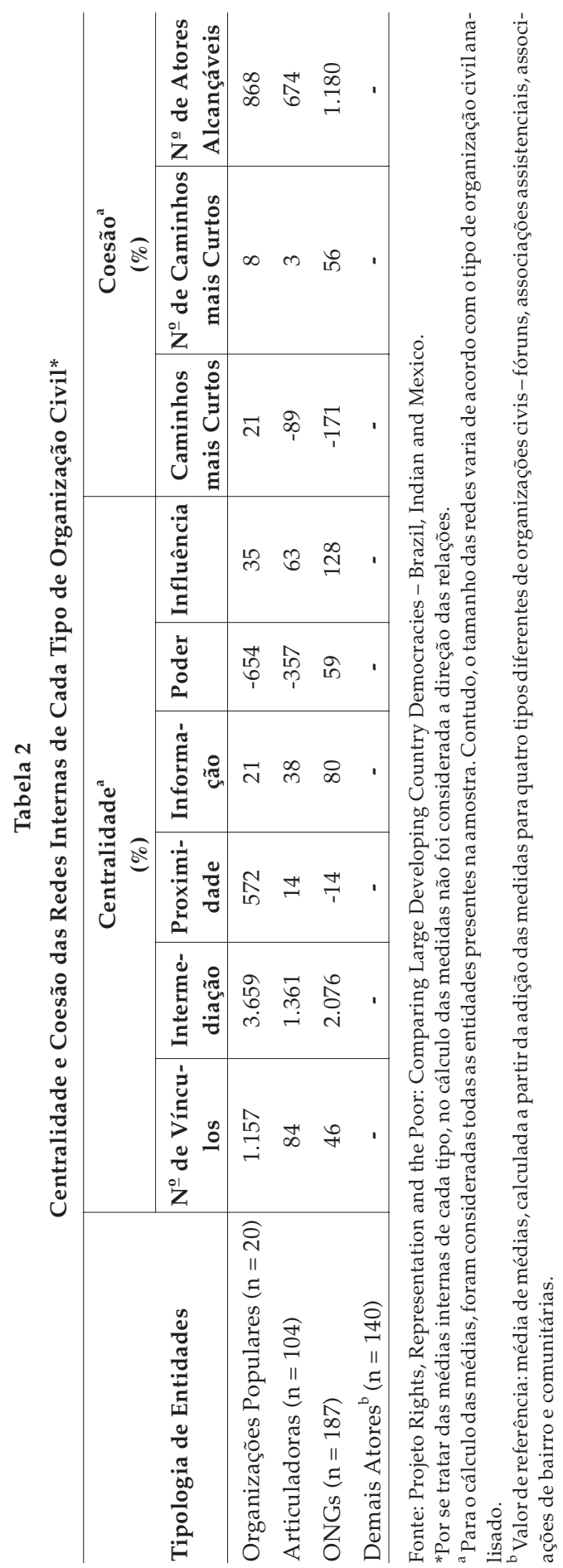


horizontalidade dos vínculos internos das organizações populares e das articuladoras; porém, diferentemente desses tipos de organizações civis, verifica-se significativa assimetria de poder ou dependência no caso das relações entre ONGs. O assunto será retomado na seção seguinte.

O terceiro recorte ilumina os vínculos preferenciais das organizações civis ao atentar para as relações estabelecidas entre tipos diferentes (Tabela 3). A análise procede por meio do recorte das redes que unem tipos de organizações civis em pares - ONGs com articuladoras, ONGs com organizações populares e assim por diante -, de modo a verificar tanto os vínculos mais "valiosos" ou procurados por diversos atores quanto as relações mais "eficientes" em termos de ampliação da capacidade de atuação dos tipos de organizações nelas envolvidos. Foram considerados apenas os ganhos obtidos em cada um dos cruzamentos entre dois tipos de organizações civis, cancelando os resultados oriundos das redes internas; isto é, consideram-se apenas os saldos da interseção entre duas redes. A tabela apresenta (i) os vínculos novos que surgiram para cada combinação em pares por tipos de organizações civis; (ii) os ganhos de intermediação trazidos por esses vínculos; e (iii) a integração ou aproveitamento real das relações que potencialmente poderiam existir em cada cruzamento. Neste caso, os tipos compreendidos na categoria Demais Atores figuram de modo separado, ou seja, são apresentados individualmente e não de forma agregada. Os resultados são apenas um ranking simples que ordena, dos melhores aos piores resultados, cada uma das três medidas para cada tipo de ator central.

Como seria de esperar, as entidades centrais cultivam vínculos preferenciais com atores igualmente centrais e desenvolvem entre si uma integração mais ampla - maior número de vínculos possíveis que estão efetivamente presentes. Assim, organizações populares encontram-se mais integradas ou aproveitam mais a potencialidade das relações que estabelecem com articuladoras e ONGs; articuladoras guardam maior integração com ONGs e organizações populares; e, por sua vez, ONGs com organizações populares e articuladoras. Embora em patamar inferior, também é possível apreciar certa relevância das relações entre organizações populares, articuladoras e ONGs, com atores de centralidade média como fóruns e entidades assistenciais. O quadro pode ser completado se trazido à tona que a procura pelas organizações mais centrais, de modo especial as articuladoras, também é dominante no caso das entidades intermediárias e periféricas. De fato, conforme 
mostrado alhures (Gurza Lavalle, Castello e Bichir, 2006), o caráter dominante da procura por organizações mais centrais por parte de entidades periféricas é consistente e diferenciado - entidades procuradas variam segundo o tipo de ator periférico - ao ponto de tornar evidente que sua estratégia de construção de relações obedece ao desafio de equacionar quais os vínculos a serem privilegiados para atingir os benefícios veiculados nos circuitos centrais.

\section{INTERPRETANDO DIFERENTES PROTAGONISMOS}

A condição central das organizações civis, a alta densidade dos seus vínculos internos, bem como os padrões de vínculos preferenciais, encobrem significados diversos, dependendo do tipo de organização civil considerada. Por outras palavras, é possível ocupar posições similares na rede e apresentar feições relacionais semelhantes por motivos diferentes. O exame integrado dos resultados dos três recortes analíticos para cada uma das três organizações civis mais centrais, complementado com a análise dos respectivos sociogramas ${ }^{24}$, permitirá iluminar esses motivos e mostrará o significado dos distintos padrões de centralidade ou protagonismos que caracterizam essas entidades.

\section{As Organizações Populares}

A despeito do relativo "sumiço" das organizações populares na literatura, esse tipo de ator é o de maior centralidade no universo das organizações civis de São Paulo, especialmente devido ao fato de ser muito procurado e, em menor medida, por ele desenvolver estratégias ativas de construção de relações (Tabela 1). Tal posição privilegiada e, como será visto adiante, a existência de vínculos com o tipo de entidade mais periférica fazem com que as organizações em questão se destaquem por sustentar relações assimétricas no universo das organizações civis.

A articulação das organizações populares entre si parece mais relevante para sua estratégia de atuação - centrada no protesto - do que a conexão com outros tipos de entidades. A rede interna dessas organizações é a mais coesa entre todas as analisadas e apresenta notável densidade de relações, atores com forte poder de intermediação e grande proximidade entre seus integrantes, cujas posições na rede são as mais equilibradas (Tabela 2). Tais características podem ser melhor compreendidas a partir do Sociograma $1^{25}$. O papel ativo das organizações populares na sua articulação interna dá lugar a uma rede binuclear: prati- 
Protagonistas na Sociedade Civil: Redes e Centralidades de Organizações...

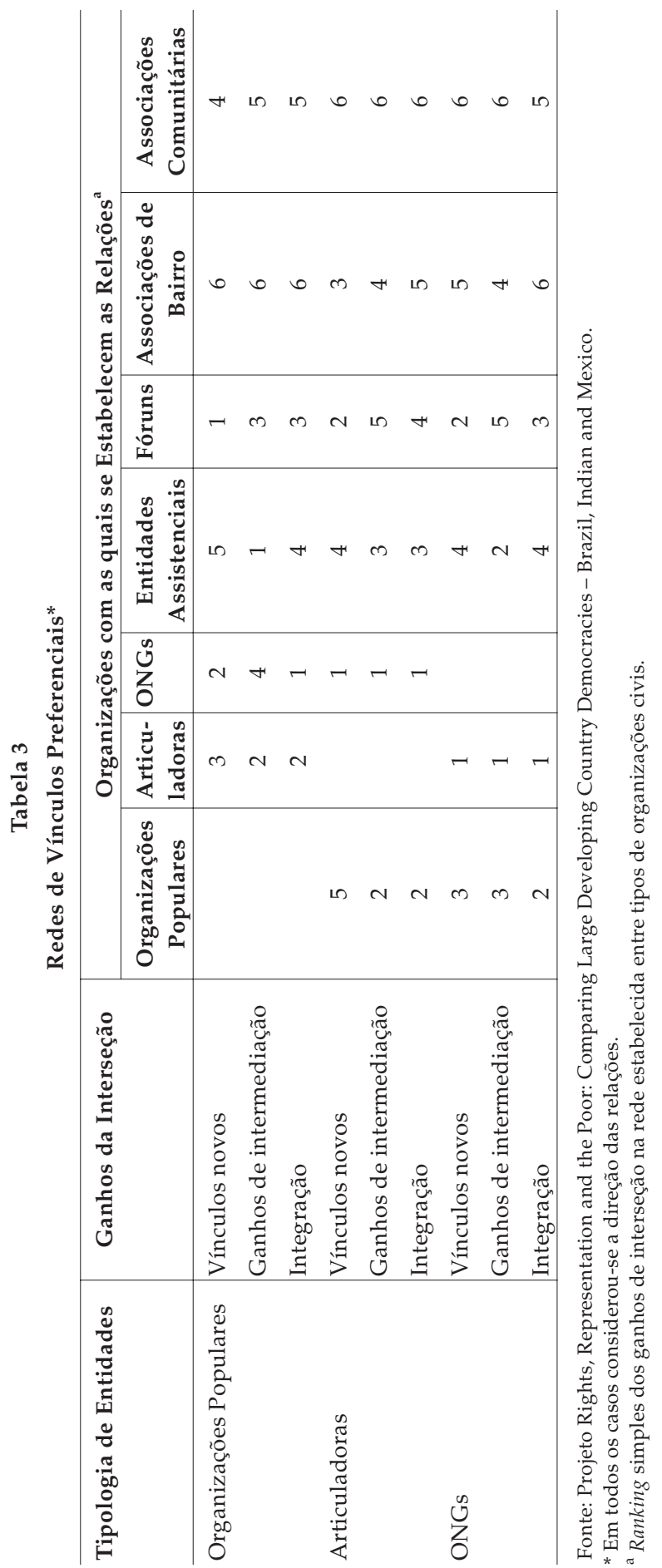


camente todos os vínculos existentes são constituídos em relação a dois atores centrais - o MST e o Movimento dos Sem-Teto do Centro $(\mathrm{mstc})^{*}$. O MST é a ponte que vincula movimentos nacionais, como o Movimento Nacional de Luta pela Moradia ( $\mathrm{mnlm}$ ), e movimentos de índole rural, como o Movimento dos Pequenos Agricultores (movpeqagri), com movimentos urbanos locais, quer dizer, da cidade de São Paulo, nucleados em torno do segundo ator - Movimento de Moradia do Centro (mmc) ou Defesa do Favelado (mdf), por exemplo. Neste caso, cumpre ressaltar, a referência central está no ator de maior capacidade de mobilização e visibilidade pública, o MST, e não em atores que atendem demandas localizadas ou apresentam afinidades temáticas, como acontece com praticamente todos os tipos de organizações civis.

Quanto aos vínculos privilegiados pelas organizações populares com outras organizações civis (Tabela 3), a proximidade com as ONGs está inscrita na origem das próprias ONGs como assessoras de movimentos sociais, mas a proximidade das organizações populares com as articuladoras é fato mais recente que não tem sido apontado na literatura. Há, ainda, outros resultados inesperados: organizações populares conferem importância mínima às relações com associações de bairro e, por sinal, trata-se de uma indiferença completamente recíproca (Gurza Lavalle, Castello e Bichir, 2006). Paradoxalmente, entre os três tipos de entidades mais centrais, as organizações populares apresentam relativamente mais vínculos com as associações comunitárias, o que contribui para a compreensão do caráter assimétrico de suas relações quando olhadas do primeiro recorte analítico.

A trajetória histórica das organizações populares levaria a supor a presença de maior (ou pelo menos de alguma) proximidade com entidades de base popular, como as associações de bairro; ainda mais se considerado que boa parte das organizações populares lida com a questão da moradia - metade no caso do Sociograma 1. Embora a análise evidencie que as organizações populares continuam a ocupar posição protagônica no seio das organizações civis - em que pese o foco dominante da literatura em outro tipo de atores -, a perda de relevância das associações de bairro

\footnotetext{
* As abreviações não são acrônimos nem seguem seus critérios de formação. Trata-se de códigos de identificação definidos para minimizar riscos de pane no software de redes, conforme os seguintes critérios: máximo de 12 caracteres; não utilização de símbolos, espaços ou acentos; sempre em caixa baixa; incorporação de número suficiente de caracteres para impedir a repetição de códigos.
} 


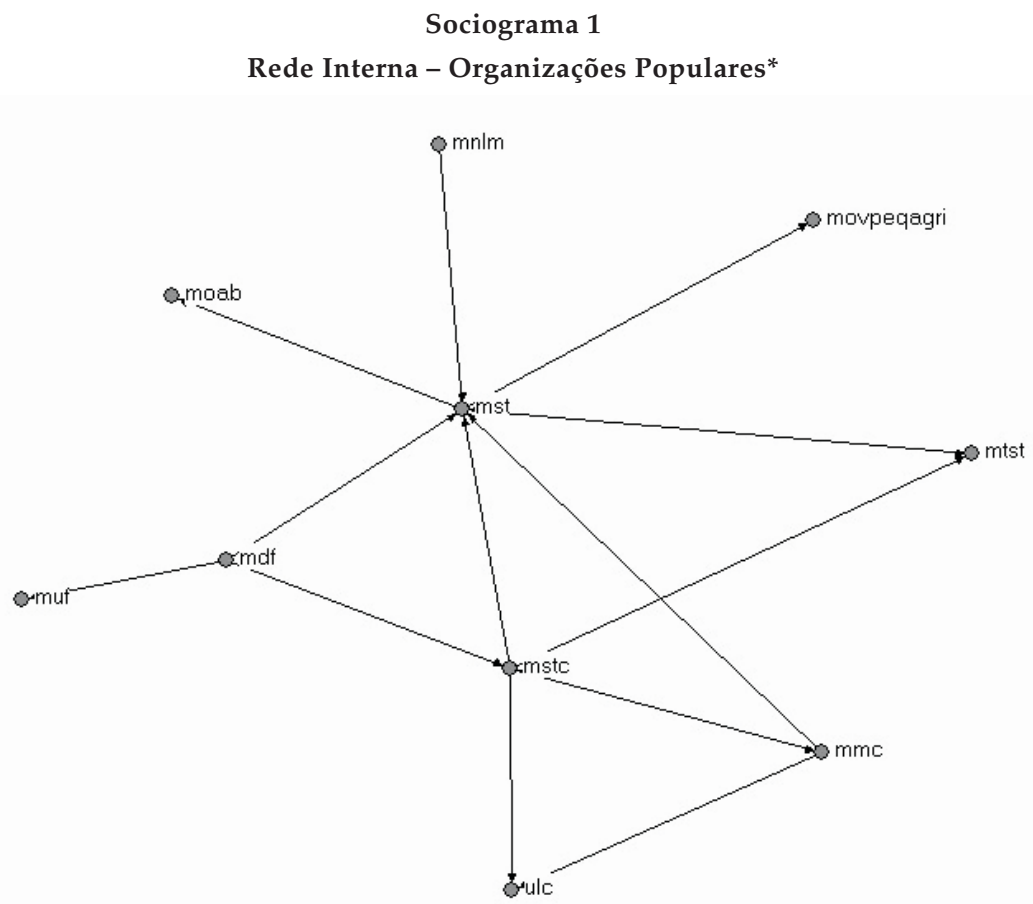

Elaboração dos autores.

* Não estão explicitadas no sociograma as entidades que não mantêm relações com outras organizações de mesmo tipo, encontramos nove organizações populares nesta situação, ou seja, $47 \%$ do total das organizações populares analisadas.

para essas organizações, e vice-versa, sugere deslocamentos inéditos no plano da ação coletiva durante os anos pós-transição; deslocamentos que ganharão contornos mais precisos mediante a interpretação dos outros tipos de organizações civis centrais.

\section{As Articuladoras}

Não surpreende a alta centralidade das articuladoras (Tabela 1) dada sua qualidade de entidades cujos públicos são outras entidades. Os efeitos de seu caráter de organizações de sócios ou membros institucionais transparecem na análise relacional: elas são relativamente distantes do universo mais amplo de entidades com as quais mantêm relações e, em se tratando de entidades assim centrais, acusam capacidade limitada de alcançar outros atores - plausivelmente além dos seus próprios membros. Como as organizações populares, e por motivos semelhantes, as articuladoras sustentam relações marcadas pela assimetria. 
As relações internas das articuladoras iluminam com maior precisão sua forma de operação. De um lado, sustentam entre si relações das mais equilibradas (ausência de dependência), configurando uma rede notavelmente densa, de outro, seus padrões internos de relacionamento obedecem a clivagens claras, diminuindo a proximidade dos seus vínculos (Tabela 2). O Sociograma ${ }^{26}$ permite visualizar tais padrões. Nele se verifica que as articuladoras ordenam suas estratégias de relacionamento por afinidades temáticas, funcionais e programáticas, não raro parcialmente sobrepostas. O nicho das entidades que tratam da questão de gênero é caso de afinidade eminentemente temática, e aquele das articuladoras de associações de bairro supõe clara afinidade funcional; entretanto, as sub-redes de movimentos populares, financiadoras do Terceiro Setor e articuladoras religiosas combinam com peso relevante mais de uma afinidade. Nos últimos três casos, as articuladoras de cada nicho trabalham em prol de atores com um perfil específico, e, a um só tempo, disputam e representam concepções diferentes do sentido da ação coletiva. Por sua vez, as relativas distância e dificuldade de alcançar atores decorrem do fato de os nichos dependerem de entidades-ponte (gatekeepers) para se vincularem a seus pares orientados por outras afinidades; notadamente, a União Brasileira de Mulheres (ubm) para as articuladoras do movimento de gênero, a Confederação Nacional de Associações de Moradores (conam) para aquelas das associações de bairro, a Central dos Movimentos Populares (cmp) para as dos movimentos, e a Rede Brasileira das Entidades Assistenciais Filantrópicas (rebraf) para as articuladoras religiosas.

O exame das relações que as articuladoras estabelecem com outras associações traz à tona algumas feições que complementam a compreensão do papel deste novo ator. As relações entre articuladoras e ONGs constituem caso único em que, nas relações entre dois tipos de atores, coincidem reciprocidade plena e importância máxima: para todas as medidas de inter-relação, as ONGs são os vínculos mais relevantes para as articuladoras e vice-versa (Tabela 3). A aliança exprime em boa medida a origem das próprias articuladoras e, simultaneamente, mostra seus vínculos mais recorrentes, reforçando seu perfil temático. Em segundo plano, as entidades em questão estabelecem vínculos com organizações populares e, depois, com organizações civis de condição intermediária - fóruns e entidades assistenciais. Cumpre notar que a existência de articuladoras de associações de bairro franqueia o seu acesso aos atores mais centrais da rede; fato evidenciado não apenas pela relativa importância das associações de bairro para as articulado- 


\section{Sociograma 2}

\section{Rede Interna das Articuladoras*}

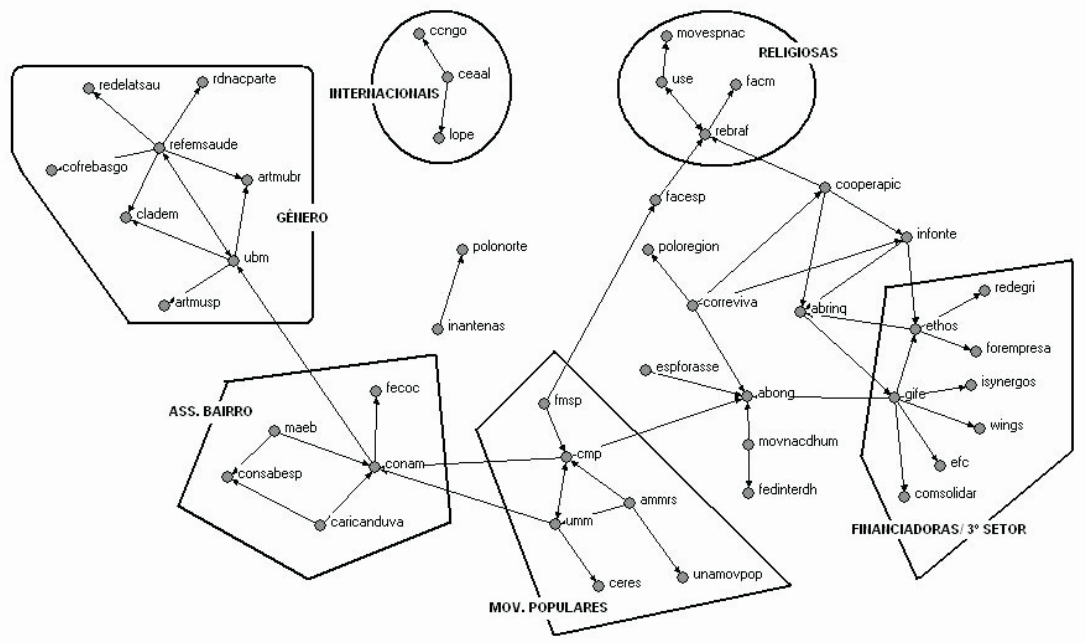

Elaboração dos autores.

* Não estão explicitadas no sociograma as entidades que não mantêm relações com outras organizações de mesmo tipo. Encontramos 53 articuladoras nesta situação, ou seja, 54\% do total de articuladoras analisadas.

ras, mas, em perspectiva inversa, pelo caráter privilegiado das relações construídas pelas primeiras com as segundas (Gurza Lavalle, Castello e Bichir, no prelo).

Os esforços de organizações civis orientados para a construção de novos atores - articuladoras - foram notavelmente bem-sucedidos. De fato, a ausência de relações entre organizações populares e associações de bairro e os achados apresentados anteriormente apontam não apenas para a existência de mudanças de envergadura na ação coletiva, mas também para a plasticidade da própria ação coletiva e para a capacidade de inovação institucional das organizações civis no sentido de incrementarem sua escala de atuação. Mais: dadas suas funções, importância e o custo de criar e manter entidades com semelhante perfil, a composição do universo das articuladoras acaba por projetar, como em jogo de sombras, as constelações de atores com maior peso na disputa pelo sentido da ação coletiva perante o Estado e perante os próprios atores sociais - o chamado campo de esquerda popular, o empresariado e as igrejas. 


\section{As ONGs}

A análise relacional revela que as atividades de advocacy das ONGs guardam conexão com uma forma de centralidade passível de ser contraposta àquela própria das organizações populares e das articuladoras: a centralidade das últimas encerra um componente passivo, enquanto a das ONGs segue um perfil ativo. Elas são o tipo de organização civil que mais constrói vínculos - mais procura do que é procurado -, além de ser menos próximo das organizações que o citam do que daquelas com as quais entabula ativamente relações (Tabela 1). A centralidade ativa torna esse tipo de entidade o mais eficiente quanto à capacidade de alcançar outras organizações ou locais da rede. Outra feição distintiva é o caráter marcadamente simétrico das relações construídas pelas ONGs, pois são as entidades que criam menor dependência nos seus relacionamentos dentro do universo das organizações civis.

A rede interna de ONGs é notavelmente coesa, a despeito de ser muito numerosa (Tabela 2). Seu perfil como construtoras ativas de relações e como entidades de advocacy adquire concreção, no plano das suas relações internas, como uma especialização temática acentuada que, no entanto, vem acompanhada mais uma vez da maior eficiência para alcançar diferentes atores, mas agora acrescida da maior disponibilidade de caminhos rápidos para alcançá-los. Apesar da coesão interna, trata-se de uma rede relativamente descentrada. O Sociograma $3^{27}$ permite verificar, precisamente, que a especificidade das relações entre ONGs está na constituição de vínculos múltiplos, dirigidos para organizações civis que trabalham em prol do mesmo tema; por exemplo, os nichos compostos por entidades dedicadas aos temas da educação, da habitação, de gênero e raça ${ }^{28}$. Também se observam sub-redes temáticas que não apresentam interação com os demais nichos: violência ou crianças deficientes. Assim, a lógica temática a um só tempo constrange e viabiliza a interação de determinados nichos com a rede mais ampla de ONGs. A despeito de as sub-redes isoladas e as ONGs se articularem seguindo uma lógica temática, a construção de vínculos múltiplos inibe a presença de atores-ponte ou intermediários indispensáveis - como ocorre no caso das articuladoras. À coesão e ao perfil temático e descentrado da rede é preciso acrescer mais duas feições. Em parte devido ao grande número de entidades na rede interna das ONGs, a proximidade entre seus integrantes é baixa e, ao contrário do que ocorre nas relações dessas entidades com as outras organizações civis, os 
vínculos internos são assimétricos, ou seja, as relações entre ONGs são consideravelmente hierárquicas.

Quando observados os vínculos privilegiados pelas ONGs com outros tipos de organizações civis (Tabela 3), emerge primeiro sua aliança com as articuladoras - já abordada -, e, depois, os vínculos estabelecidos com organizações populares, seguidos daqueles construídos com fóruns e entidades assistenciais. Relações com associações que obedecem à lógica de demandas populares específicas, como as comunitárias e associações de bairro, mostram-se pouco importantes. Por isso, diferentemente das organizações populares e das articuladoras, ONGs não acusam relações assimétricas no conjunto da rede.

A idéia de as ONGs trabalharem em rede encontra-se amplamente presente na literatura, todavia, quando assumidos os pressupostos da análise de redes, tal afirmação torna-se um truísmo, visto que o ponto de partida é o caráter relacional do mundo. Os resultados permitem qualificar melhor o perfil das ONGs como construtoras de vínculos ou atores centrais ativos. A combinação entre a simetria das relações das

Sociograma 3

\section{Rede Interna ONGs*}

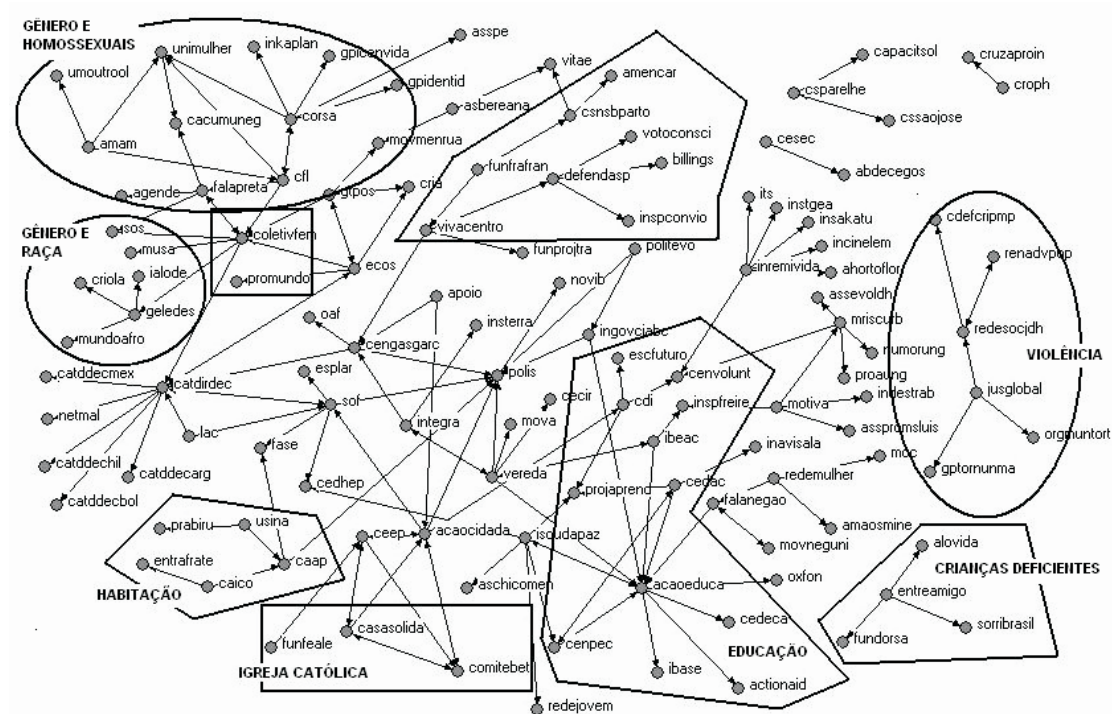

Elaboração dos autores.

* Não estão explicitadas no sociograma as entidades que não mantêm relações com outras organizações de mesmo tipo. Encontramos 59 ONGs nesta situação, ou seja, 33\% do total de ONGs analisadas. 
ONGs com a rede como um todo e a dependência gerada pelos vínculos com seus pares contrasta com o padrão inverso dos outros dois tipos de organizações civis centrais que aliam horizontalidade nas relações internas com aguda assimetria nos vínculos estabelecidos dentro do conjunto das organizações civis. Semelhante contraste decorre não apenas da centralidade ativa, mas de seletividade que privilegia apenas outras entidades centrais - entidades periféricas e intermediárias não são procuradas. De fato, a aliança entre ONGs e articuladoras reforça esse perfil ao sinalizar emblematicamente a trajetória das primeiras e a consolidação do seu protagonismo no contexto pós-transição: originadas como entidades de assessoria aos movimentos populares (organizações populares), acabaram por se desvencilhar da sua missão inicial assumindo funções próprias na disputa da agenda pública e da formulação, fiscalização e, por vezes, implantação de políticas públicas. As funções assumidas e politicamente construídas ao longo dessa trajetória correm paralelas a sua acentuada especialização temática e a sua diferenciação e hierarquização internas.

\section{CONCLUSÃO}

A interpretação dos achados apresentados neste artigo ilumina de ângulos diversos a atuação das organizações civis mais centrais e aponta para lacunas no estado do conhecimento desses atores; lacunas que, para serem sanadas, exigem a construção coletiva de uma vasta agenda de pesquisa, na qual abordagens relacionais constituem estratégias conceituais e metodológicas de enorme valia. A abordagem relacional mostra que - pelo menos em São Paulo - o universo das organizações civis é hierárquico e desigual quanto às capacidades de ação e de interlocução. Organizações populares, articuladoras e ONGs são os grandes protagonistas da rede, com padrões de centralidade diferenciados, quer dizer, os atores que, por motivos diferentes, se apresentam como referência para entidades menos centrais ou francamente periféricas. Por sua vez, as organizações civis mais centrais são simultaneamente aquelas com investimentos maiores na construção de relações com seus próprios pares, e aquelas mais procuradas pelas próprias entidades centrais, bem como pelas entidades periféricas e intermediárias.

Neste artigo há evidências tanto do caráter impreciso ou apressado de alguns consensos na literatura quanto de transformações de envergadura sem tratamento ou estudo adequado. Movimentos sociais (organizações populares), por exemplo, distam de ter submergido no ma- 
rasmo em que os prostrou a literatura a partir da onda de balanços que marcara a passagem dos anos 1980 para a década seguinte. Eles são os atores mais centrais no universo das organizações civis pesquisadas e, no entanto, experimentaram transformações no seu perfil. De outro lado, as articuladoras são produto notável de uma estratégia bem-sucedida de criação de atores que reflete o adensamento e diferenciação funcional do universo das organizações civis. Sua centralidade não apenas atesta a capacidade de construção institucional das organizações civis, em particular das ONGs, mas ilumina a plasticidade da ação coletiva no sentido de inovar para escalar demandas e problemas, bem como para representar interesses e perfilar agendas compartilhadas por constelações amplas de atores sociais.

Hierarquização e desigualdades estruturais na capacidade de ação e comunicação, mas sobretudo o caráter cumulativo das vantagens estruturais, apontados nestas páginas, sugerem críticas e levantam uma série de problemas para a teoria da sociedade civil, bem como a sua junção com o debate em curso no campo da teoria democrática - não abordados aqui. O quão corrosivos possam eventualmente ser achados como estes depende, em boa medida, do grau de exigências normativas introduzidas pela teoria, bem como do papel que tais exigências desempenham no diagnóstico do mundo. Seja como for, os resultados são persuasivos sobre dois aspectos passíveis de interpretação a partir de diferentes registros teóricos: primeiro, os alcances da atuação das organizações civis mal podem ser compreendidos se desconsiderados os processos de diferenciação funcional impulsionados intencionalmente por esses atores para incrementar suas chances de incidência nas instâncias pertinentes de tomada de decisões ou na conformação da agenda pública; segundo, a ação coletiva no contexto da pós-transição acusa mudanças relevantes, mas sem abordagens sistemáticas e comparativas do universo das organizações civis, o tratamento do assunto carece de parâmetros e corre o risco de descansar em apreciações impressionistas.

(Recebido para publicação em abril de 2007)

(Versão definitiva em junho de 2007) 


\section{NOTAS}

1. Entre 1970 e 1990, as contribuições privadas e governamentais transferidas mediante as ONGs do hemisfério norte a suas homólogas do hemisfério sul aumentaram significativamente, passando de 1.000 a 7.200 milhões de dólares. De fato, no início da década de 1990,13\% das contribuições oficiais do hemisfério norte para o hemisfério sul eram alocadas por intermediação das ONGs (PNUD, 1993:100 e 106).

2. Para uma exceção em que são submetidos à análise conflitos, diferenças e eventuais implicações negativas das sociedades civis reais, ver o volume organizado por Alexander (1998).

3. Dois componentes normativos definem as fronteiras da sociedade civil na literatura, a saber, autolimitação e autonomia dos atores societários (ver Cohen e Arato, 1995; Olvera, 2003). Não se sustenta neste artigo qualquer crítica geral ao papel da teoria na construção de conhecimento, apenas atenta-se para os custos cognitivos de certas formulações teóricas de caráter normativo da chamada sociedade civil.

4. Para um exame autorizado das vantagens analíticas da análise de redes no estudo dos movimentos sociais, ver o volume organizado por Diani e McAdam (2003); em relação ao debate no Brasil, ver Gurza Lavalle, Castello e Bichir (2006).

5. Informações metodológicas mais detalhadas e outros resultados da pesquisa podem ser encontrados em Houtzager et alii (2002), Houtzager, Gurza Lavalle e Acharya (2003; 2004); Gurza Lavalle, Houtzager e Acharya (2004); Gurza Lavalle, Houtzager e Castello (2006a; 2006b).

6. Fóruns são espaços de encontro e adensamento de agendas temáticas para orientar a atuação de organizações civis. Entidades assistenciais trabalham prestando serviços diretos a terceiros, concebidos como públicos-alvo a partir de critérios de vulnerabilidade. Associações de bairro são atores com identidade territorial voltados para a projeção de demandas ao poder público a respeito de infra-estrutura urbana. Associações comunitárias trabalham para os próprios membros da associação seguindo a lógica das associações mutualistas ou de ajuda mútua, e constituem nichos de convivência específicos (centro da juventude, clubes de idosos, de jogadores de bocha etc.). Para uma exposição detalhada da tipologia expandida, ver Gurza Lavalle, Castello e Bichir (2006).

7. Por exemplo: "[...] as ONGs passaram a ter muito mais importância nos anos 90 do que os próprios movimentos sociais" (Gohn, 2003:22). Ver também Paz (2005:8-11).

8. Na caracterização de Carvalho (1998:87-88), as ONGs regem-se pelo princípio da solidariedade, por ações de multiple advocacy, de empowerment, e determinam fortemente a agenda pública. A importância das redes ou a caracterização do estilo de trabalho das ONGs com base na noção de redes é constante na literatura (Fernandes, 1994:128-131; Scherer-Warren, 1996; Landim, 1996:xiv).

9. Há quem ainda descreva a relação entre as ONGs e seus beneficiários em termos que parecem mais apropriados para as décadas de 1970 e 1980: “[...] na maior parte [trabalhando] junto a grupos populares discriminados ou marginalizados [...]" (Gohn apud Coelho, 2000:xv). Também até há alguns anos e pelas prioridades das agências financiadoras "[...] a razão de ser de muitas ONGs estava associada a sua aliança com organizações populares" (Casanovas Sainz e García Chacón, 2000:63-67). Ver o trabalho de Landim (2002) para uma reconstrução notável da gênese das ONGs como 
entidades de assessoria e apoio nos anos 1970, e sua diversificação temática e adensamento organizativo na forma de sub-redes, o que teria levado essas entidades - em processo tortuoso - a assumir para si a identidade de ONGs e a se desvencilhar progressivamente do seu enraizamento (e indiferenciação) nos atores populares. A mesma autora afirma, no entanto, que o contato com grupos populares continua a ser relevante para as ONGs (Landim, 1998).

10. É possível, ainda, encontrar especificações dos beneficiários do trabalho das ONGs em registro semelhante ao da assistência, próprio de entidades beneficentes (ver Coelho, 2000:60).

11. Para um balanço acessível das principais perspectivas, ver Gohn (1997).

12. Ver, por exemplo, os balanços desenvolvidos por Cardoso (1994:81-90), Cunha (1993:134-135) e Nunes (1987:92-94).

13. Segundo Gohn (2003:13-32), por exemplo, nos anos 1990 não há processos de mobilização de massa, mas de mobilização pontual dentro da lógica da participação cidadã, e não do ativismo popular coletivo.

14. Embora boa parte das articuladoras seja pensada como $\mathrm{ONG}$, algumas poderiam ser assimiladas às organizações populares; porém, a atuação dessas entidades na coordenação e representação de interesses de outras organizações civis, e não na mobilização direta de segmentos da população, valida a distinção. De modo emblemático, todas as articuladoras de movimentos sociais contempladas na amostra nasceram após a transição: Central de Movimentos Populares (1993), Fórum dos Mutirões de São Paulo (1992), União dos Movimentos de Moradia (1987) e Associação dos Movimentos de Moradia da Região Sul (1994).

15. No Brasil, trata-se de estratégia analítica de incipiente difusão. Os trabalhos de Marques $(2000 ; 2003)$ são pioneiros e constituem a referência mais relevante de aplicação bem-sucedida da análise de redes ao campo das políticas públicas.

16. Nesse sentido, a análise de redes transforma em um dado estrutural aquilo que as teorias dos movimentos sociais vinculadas às perspectivas da mobilização de recursos e do processo político têm apontado sistematicamente, a saber, o contexto ou ambiente é fundamental para entender a ação coletiva (ver Davis et alii, 2005:4-40). Contudo, a análise de redes apresenta a vantagem analítica de contemplar os outros atores não como "entorno" ou dado externo, mas como parte da definição estrutural do ator em questão.

17. Para uma discussão conceitual a respeito das medidas de centralidade e coesão utilizadas usualmente nas análises de redes sociais, ver Hanneman (2001).

18. No processamento das medidas foi utilizado o software Ucinet (Borgatti, Everett e Freeman, 2002).

19. Aqui se resolveu diferenciar a origem e o destino dos vínculos. Apenas no caso de algumas medidas, por motivos técnicos, as relações presentes na rede foram consideradas de modo simétrico.

20. No trabalho de campo, foram entrevistadas 229 organizações civis, mas devido a critérios metodológicos apenas 202 foram contempladas na análise de redes.

21. São bem conhecidas as circunstâncias em que a técnica bola de neve oferece vantagens metodológicas (ver Atkinson e Flint, 2003; Goodman, 1961; Sudman e Kalton, 1986). Para uma análise das vantagens de se utilizá-la especificamente no estudo de 
organizações civis, ver Houtzager, Gurza Lavalle, Acharya (2004:288-291), e Gurza Lavalle, Houtzager e Acharya (2005). Informações mais detalhadas sobre os critérios de construção da amostra utilizando a bola de neve podem ser consultadas em Houtzager, Gurza Lavalle e Acharya (2003).

22. Todos os vínculos levantados constituem, efetivamente, uma única rede ou componente. Para uma análise das suas principais características, ver Gurza Lavalle, Castello e Bichir (2006).

23. Todas as medidas a serem apresentadas foram estimadas mediante a aplicação de diferentes ponderadores para controlar os efeitos decorrentes do peso dos distintos tipos de organização civil na amostra. Aqui são apresentadas apenas as porcentagens calculadas a partir das médias ponderadas e sempre em relação aos Demais Atores.

24. Nos sociogramas, cada ponto representa uma organização civil e os traços representam as relações existentes entre essas organizações. O comprimento das linhas e a representação visual da posição do ator no desenho não representam qualquer distância entre esses atores, mas apenas a presença ou ausência de vínculo.

25. Atores: mdf - Movimento de Defesa dos Favelados; mmc - Movimento de Moradia do Centro; mnlm - Movimento Nacional de Luta pela Moradia; moab - Movimento dos Atingidos por Barragens; movpeqagri - Movimento dos Pequenos Agricultores; mst - Movimento dos Sem-Terra; mstc - Movimento dos Sem-Teto do Centro; mtst Movimento dos Trabalhadores Sem-Teto; muf - Movimento de Unificação das Favelas; ulc - Unificação de Lutas de Cortiços.

26. Atores: abong - Associação Brasileira de ONGs; abrinq - Fundação Abrinq; ammrs Associação dos Movimentos de Moradia da Região Sudeste; artmubr - Articulação de Mulheres Brasileiras; artmusp - Articulação de Mulheres de São Paulo; caricanduva - Câmara do Vale do Aricanduva; ccngo - Collective Consultation of NGOs; ceaal - Conselho de Educação de Adultos da América Latina; ceres - Coalition for Environmentally Responsible Economies; cladem - Comitê Latino-Americano e do Caribe para a Defesa dos Direitos da Mulher; cmp - Central de Movimento Populares; cofrebasgo - Comissão da Federação Brasileira das Associações de Ginecologia e Obstetrícia; comsolidar - Comunidade Solidária; conam - Confederação Nacional de Associações de Moradores; consabesp - Conselho Coordenador das Sociedades Amigos de Bairro, Cidades e Vilas do Estado de São Paulo; cooperapic-Cooperativa de Promoção à Cidadania; correviva - Corrente Viva; efc - European Foundation Center; espforasse - Espaço Formação e Assessoria; ethos - Ethos; facesp - Federação das Associações Comerciais do Estado de São Paulo; facm - Federação de Associações Cristãs de Moços; fecoc - Frente Continental de Organizações Comunitárias; fedinterdh - Federação Internacional de Direitos Humanos; fmsp - Fórum dos Mutirões de São Paulo; forempresa - Fórum Empresa; gife - Grupo de Institutos, Fundações e Empresas; inantenas - Instituto Antenas; infonte - Instituto Fonte; isynergos Instituto Synergos; lope - Rede Latino-Americana; maeb - Movimento das Associações e Entidades de Bairro; movespnac - Movimento Espírita Nacional (órgão); movnacdhum - Movimento Nacional de Direitos Humanos; polonorte - Pólo Norte; poloregion - Pólo Regional; rdnacparte - Rede Nacional de Parteiras; rebraf - Rede Brasileira das Entidades Assistenciais; redegri - Rede GRI (Global Reporting Initiative); redelatsau - Rede Latino Americana de Saúde; refemsaude - Rede Feminista de Saúde; ubm - União Brasileira de Mulheres; umm - União dos Movimentos de Mora- 
dia; unamovpop - União Nacional de Movimentos Populares; use - União das Sociedades Espíritas; wings - Wings.

27. Atores: abdecegos - Associação Brasileira de Desporto para Cegos; acaocidada Ação da Cidadania; acaoeduca - Ação Educativa; actionaid - Action Aid; agende Ações em Gênero, Cidadania e Desenvolvimento; ahortoflor - Associação Horto Florestal; Alovida - Alô Vida; Amam - Associação das Mulheres que Amam Mulheres; amaosmine - Associação Mãos Mineiras; amencar - Amparo ao Menor Carente; apoio - Associação Paranaense de Orientação, Integração e Ofícios; asbereana Associação Bereana; aschicomen - Associação Chico Mendes; assevoldh - Associação Evoluir e Desenvolvimento Humano; asspe - Associação Santista de Pesquisa, Prevenção e Educação em DST / Aids; asspromsluis - Associação Pró-Moradia do Jardim São Luis; billings - Billings que Eu te Quero Viva; caap - Centro de Assessoria à Auto-Gestão Popular; cacumuneg - Casa da Cultura da Mulher Negra; caico-Centro de Apoio à Iniciativa Comunitária; capacitsol - Capacitação Solidária; casasolida - Casa da Solidariedade; catddecarg - Católicas pelo Direito de Decidir - Argentina; catddecbol - Católicas pelo Direito de Decidir - Bolívia; catddechil - Católicas pelo Direito de Decidir - Chile; catddecmex - Católicas pelo Direito de Decidir - México; catdirdec - Católicas pelo Direito de Decidir; cdefcripmp - Centro de Defesa da Criança Padre Marcos Pordrini; cdi - Comitê para a Democratização da Informática; cecir-Centro Cidra Romano; cedac-Centro de Desenvolvimento Agroecológico do Cerrado; cedeca - Centro de Defesa dos Direitos da Criança e do Adolescente; cedhep - Centro de Direitos Humanos de Educação Popular; ceep - Centro de Educação, Estudos e Pesquisas; cengasgarc - Centro Gaspar Garcia; cenpec - Centro de Estudos e Pesquisas em Educação e Ação Comunitária; cenvolunt - Centro de Voluntariado; cesec - Centro de Estudos de Segurança e Cidadania; cfl - Coletivo Feminista de Lésbicas; coletivfem - Coletivo de Feministas Lésbicas; comitebet - Comitê Betinho; corsa - Cidadania, Orgulho, Respeito, Solidariedade e Amor; cria - Centro de Referência em Informação Ambiental; criola - CRIOLA; croph - Centro de Promoção Humana; cruzaproin - Cruzada Pró-Infância; csnsbparto - Centro Social Nossa Senhora do Bom Parto; csparelhe - Centro Social de Parelheiros; cssaojose Centro Social São José; defendasp - Defenda São Paulo; ecos - Espaço, Cidadania e Oportunidades Sociais; entrafrate - Entraide et Fraternité (Bélgica); entreamigo Entreamigos; escfuturo - Escola do Futuro; esplar-Centro de Pesquisa e Assessoria; falanegao - Fala Negão; falapreta - Fala Preta; fase - Federação de Órgãos para Assistência Social e Educacional; fundorsa - Fundação Orsa; funfeale - Fundação Fé e Alegria; funfrafran - Fundação Francisca Franco; funprojtra - Fundação Projeto Travessia; geledes - Instituto da Mulher Negra; gpicenvida - Grupo de Incentivo à Vida; gpidentid - Grupo Identidade; gptornunma - Grupo Tortura Nunca Mais; gtpos - Grupo de Trabalho e Pesquisa em Orientação Sexual; ialode - Ialodê (Bahia); ibase - Instituto Brasileiro de Análises Sociais e Econômicas; ibeac - Instituto Brasileiro de Estudos e Apoio Comunitário; inavisala - Instituto Avisa Lá; incinelem Instituto 5 Elementos; indestrab - Instituto de Desenvolvimento do Trabalhador; ingovciabc - Instituto de Governo e Cidadania do ABC; inkaplan - Instituto Kaplan; inremivida - Instituto Recicle Milhões de Vidas; insakatu - Instituto Akatu; inspconvio - Instituto São Paulo contra a Violência; inspfreire - Instituto Paulo Freire; insterra Instituto Terra; instgea - Instituto GEA-Ética e Meio Ambiente; integra - Asociación Cultural Integra; isoudapaz - Instituto Sou da Paz; its - Instituto de Tecnologia So- 
cial; jusglobal - Justiça Global; lac - Liga de Assessoria Comunitária; moc - Movimento de Organização Comunitária (Bahia); motiva - Instituto Motiva; mova - Movimento de Alfabetização; movmenrua - Movimento de Meninos e Meninas de Rua; movneguni - Movimento Negro Unificado; mriscurb - Movimento de Prevenção aos Riscos Urbanos; mundoafro - Mundo Afro (Uruguai); musa - Mulher e Saúde (Belo Horizonte); netmal - Núcleo de Estudos Tecnológicos da Mulher na América Latina; novib-Oxfam Novib; numorung - Núcleo Morungaba; oaf-Organização do Auxílio Fraterno; orgmuntort - Organização Mundial Contra a Tortura; oxfam OXFam International; polis - Instituto Polis; politevo - Associação Politevo Rede Local de Economia Solidária; prabiru - Instituto Peabirú; proaung - Pro Aung; projaprend - Projeto Aprendiz; promundo - Pró-Mundo; redejovem - Rede Jovem; redemulher - Rede Mulher; redesocjdh - Rede Social de Justiça e Direitos Humanos; renadvpop - Rede Nacional de Advogados e Advogadas Populares; sof - Sempre Viva Organização Feminina; sorribrasil - Sorri-Brasil; sos - SOS Mata Atlântica; umoutrool - Um Outro Olhar; unimulher - União de Mulheres; usina - Centro de Trabalhos para o Ambiente Habitado; vereda - Centro de Estudos em Educação; vitae - Apoio à Cultura, Educação e Promoção Social; vivacentro - Viva o Centro; votoconsci - Voto Consciente.

28. Foram destacados apenas os maiores nichos temáticos para permitir a visibilidade da informação apresentada.

\section{REFERÊNCIAS BIBLIOGRÁFICAS}

ALEXANDER, Jeffrey. (1998), Real Civil Societies: Dilemmas of Institutionalization. London/Thousand Oaks, Sage.

ATKINSON, R. e FLINT, J. (2003), “Accessing Hidden and Hard-to-Reach Populations: Snowball Research Strategies". Social Research Update, no 33, disponível também em www.soc.surrey.ac.uk/sru/SRU33.html.

BORGATTI, S. P., EVERETT, M. G. e FREEMAN, L. C. (2002), Ucinet - Software of Social Network Analysis User's Guide. Harvard, Analytic Technologies, Inc.

CARDOSO, Ruth Corrêa Leite. (1994), "A Trajetória dos Movimentos Sociais", in E. Dagnino (org.), Anos 90 - Política e Sociedade no Brasil. São Paulo, Brasiliense, pp. $81-90$

CARVAlHO, Maria do Carmo Brant. (1998), "Sociedade Civil, Estado e Terceiro Setor". São Paulo em Perspectiva, vol. 12, no 4.

CASANOVAS SAINZ, Roberto e GARCÍA CHACÓN, Oscar. (2000), Las ONGs Latinoamericanas y los Desafíos del Desarrollo Organizacional. Bolívia, ICCO/ PROACTIVA/IDEPRO.

COELHO, Simone de Castro Tavares. (2000), Terceiro Setor: Um Estudo Comparado entre Brasil e Estados Unidos. São Paulo, Senac. 
COHEN, Jean e ARATO, Andrew. (1995), Sociedad Civil y Teoría Política. México, Fondo de Cultura Económica.

CUNHA, Flávio S. (1993), “Movimentos Sociais Urbanos e a Redemocratização: A Experiência do Movimento Favelado de Belo Horizonte". Novos Estudos, no 35, pp. 134-135, 142.

DAVIS, Gerald, McADAM, Dough, SCOTT, Richard e ZALD, Mayer. (2005), Social Movements and Organization Theory. New York, Cambridge University Press.

DIANI, Mario e McADAM, Dough. (2003), Social Movements and Networks. Relational Approaches to Collective Action. Oxford, Oxford University Press.

EMIRBAYER, Mustafa. (1997), "Manifesto for a Relational Sociology". American Journal of Sociology, vol. 103, no 2, pp. 281-317.

EVERS, Tilman. (1984), "Identidade - A Face Oculta dos Movimentos Sociais". Novos Estudos, no 4, pp. 11-23.

FELTRAN, Gabriel. (2005), Desvelar a Politica na Periferia: História de Movimentos Sociais em São Paulo. São Paulo, Associação Editorial Humanitas/Fapesp.

FERNANDES, Rubem César. (1994), Privado, porém Público - O Terceiro Setor na América Latina. Rio de Janeiro, Relume Dumará/Civicus.

GOHN, Maria da Glória. (1997), Teorias dos Movimentos Sociais - Paradigmas Clássicos e Contemporâneos. São Paulo, Edições Loyola.

(org.). (2003), Movimentos Sociais no Início do Século XXI. Petrópolis, Vozes.

GOODMAN, L. (1961), "Snowball Sampling". Annals of Mathematical Statistics, vol. 32, no 1.

GURZA LAVALLE, Adrian, CASTELLO, Graziela e BICHIR, Renata M. (2004), “Quando Novos Atores Saem de Cena: Continuidades e Mudanças na Centralidade dos Movimentos Sociais". Cultura e Política, vol. 10, o 2.

. (2006), Os Bastidores da Sociedade Civil - Protagonismo, Redes e Afinidades no Seio das Organizações Civis. São Paulo, Cebrap (mimeo).

(no prelo), "The Backstage of Civil Society: Roles, Centrality and Networks within Civil Organization in São Paulo". IDS Working Paper Series, Brighton, Institute of Development Studies.

GURZA LAVALLE, Adrian, HOUTZAGER, Peter e ACHARYA, Arnab. (2004), "Lugares e Atores da Democracia - Arranjos Institucionais Participativos e Sociedade Civil em São Paulo", in V. Schattan e M. Nobre (orgs.), Participação e Deliberação - Teoria Democrática e Experiências Institucionais no Brasil Contemporâneo. São Paulo, Editora 34.

(2005), “Beyond Comparative Anecdotalism: Lesson on Civil Society and Participation from São Paulo, Brazil". World Development Journal, vol. 33, no6, pp. 951-964.

GURZA LAVALLE, Adrian, HOUTZAGER, Peter e CASTELLO, Graziela. (2006a), “Democracia, Pluralização da Representação e Sociedade Civil”. Lua Nova, no 67.

(2006b), “Representação Política e Organizações Civis - Novas Instâncias de Mediação e os Desafios da Legitimidade". Revista Brasileira de Ciências Sociais, vol. 21, no 60 . 
HANNEMAN, Robert A. (2001), "Introduction to Social Network Methods". Disponível em http:/ /faculty.ucr.edu/ hanneman/SOC157/NETTEXT.PDF.

HOUTZAGER, P., COLLIER, R. B., HARRISS, J. e GURZA LAVALLE, A. (2002), “Rights, Representation and the Poor: Comparisons across Latin America and India". Destin Working Paper 02-31, London, London School of Economics.

HOUTZAGER, P., GURZA LAVALlE, A. e ACHARYA, A. (2003), “Who Participates? Civil Society and the New Democratic Politics in São Paulo, Brazil". IDS Working Paper 210, Brighton, Institute of Development Studies.

. (2004), “Atores da Sociedade Civil e Atores Políticos: Participação nas Novas Políticas Democráticas em São Paulo", in L. Avritzer (ed.), O Associativismo em São Paulo. São Paulo, Unesp, vol. 1, pp. 257-322.

LANDIM, Leilah. (1996), "Notas para um Perfil das ONGs", in L. Landim e L. L. Cotrim (orgs.), ONGs: Um Perfil. São Paulo/Rio de Janeiro, Abong/Iser, pp. IX-XX.

(1998), “Experiência Militante': Histórias das Assim Chamadas ONGs", in L. Landim (org.), Ações em Sociedade - Militâncias, Caridade, Assistência, etc. Rio de Janeiro, ISER/NAU, pp. 23-88.

. (2002), "Múltiplas Identidades das ONGs", in S. Haddad (org.), ONGs e Universidades - Desafios para Cooperação na América Latina. São Paulo, Abong, pp. 17-50.

MARQUES, Eduardo. (2000), Estado e Redes Sociais: Permeabilidade e Coesão nas Políticas Urbanas no Rio de Janeiro. Rio de Janeiro/São Paulo, Revan/Fapesp.

. (2003), Redes Sociais, Instituições e Atores Políticos no Governo da Cidade de São Paulo. São Paulo, Annablume.

MARTELETO, Regina Maria, RIBEIRO, Leila Beatriz e GUIMARÃES, Cátia. (2002), “Informação em Movimento. Produção e Organização do Conhecimento nos Espaços Sociais". Civitas, ano 2, no 1.

MELUCCI, Alberto. (1989), “Um Objetivo para os Movimentos Sociais?”. Lua Nova, no 17, pp. 49-66.

MENDONÇA, Daniel. (2002), “Para Além da Lei. Agonismo como Princípio de Ação dos Movimentos Sociais". Civitas, ano 2, № 1.

NUNES, Edson. (1987), “Movimentos Populares na Transição Inconclusa”. Lua Nova, no 13, pp. 92-94.

OLVERA, Alberto. (2003), Sociedad Civil, Esfera Pública y Democratización en América Latina: México. México, Universidad Veracruzana/Fondo de Cultura Económica.

PAZ, Rosângela. (2005), “Organizações Não-Governamentais: Um Debate sobre a Identidade Política das Associadas à Abong". Cadernos Abong, no 33.

PROGRAMA DAS NAÇÕES UNIDAS PARA O DESENVOLVIMENTO - PNUD. (1993), Informe sobre Desarrollo Humano. Madrid, PNUD/CIDEAL.

RUCHT, Dieter. (2002), "Sociedade como Projeto - Projetos na Sociedade. Sobre o Papel dos Movimentos Sociais". Civitas, vol. 2, № 1.

SADER, Eder. (1988), Quando Novos Personagens Entram em Cena - Experiências, Falas e Lutas dos Trabalhadores da Grande São Paulo (1970-80). São Paulo, Paz e Terra. 
Protagonistas na Sociedade Civil: Redes e Centralidades de Organizações...

SCHERER-WARREN, Ilse. (1996), Redes de Movimentos Sociais. São Paulo, Loyola.

SCOTT, J. (1992), Social Network Analysis. Newbury Park, Sage.

SOBOTTKA, Emil A. (2002), “Organizações e Movimentos Sociais”. Civitas, vol. 2, no 1.

SUDMAN, S. e KALTON, G. (1986), “New Developments in the Sampling of Special Populations". Annual Review of Sociology, no 12, pp. 401-429.

TOURAINE, Alain. (1989), “Os Novos Conflitos Sociais - Para Evitar Mal-Entendidos”. Lua Nova, no 17, pp. 5-18.

WASSERMAN, S. e FAUST, K. (1994), Social Network Analysis: Methods and Applications. Structural Analysis in the Social Sciences. Cambridge, Cambridge University Press, vol. 8.

\section{ABSTRACT \\ Leading Actors within Civil Society: Networks and Centralities of Civil Organizations in São Paulo}

Using network analysis, this article identifies the main leading collective actors within civil society, and especially their different logics of performance and the dynamics of interaction amongst them. The findings of a survey of 202 civil organizations in the city of São Paulo showed that NGOs, coordinating bodies and social movements form the group of actors with the greatest capacity for action within the universe of civil organizations. Analyzed in a relational perspective, the three types of actors manifested themselves as the most central and characterized by an accumulation of structural advantages within the universe researched. The article shows that their centrality results from different factors, as well as that they fulfill different roles and differ in importance for other civil organizations which are peripheral or have an intermediate centrality in the network.

Key words: networks; civil society; São Paulo 


\section{RÉSUMÉ}

Acteurs de la Société Civile: Réseaux et Centralités d'Organisations Civiles à São Paulo

Dans cet article, on cherche à repérer les principaux acteurs de la société civile de la ville de São Paulo, Brésil, et surtout leurs différentes logiques d'action et leurs dynamiques internes d'interaction. À partir des résultats d'un survey effectué dans la ville de São Paulo auprès de 202 organisations civiles, on a trouvé que des organisations non-gouvernementales - des ONGs, de fonction, pratiquement délaissées par la littérature - et des mouvements sociaux cumulent plusieurs avantages structurels dans le réseau et constituent les grands acteurs de l'univers des organisations civiles étudié. Pourtant, pour des raisons qu'on expose dans cet article, ces organisations sont centrales à plusieurs titres, jouent des rôles divers dans le réseau et ont une importance inégale par rapport à d'autres types d'entités civiles périphériques ou de centralité intermédiaire.

Mots-clé: analyse de réseaux, société civile; ville de São Paulo 